\title{
FATORES ASSOCIADOS AO NIVELL DE GASTO COM SAÚDE: A IMPORTÂNCIA DO MODELO DE PAGAMENTO HOSPITALAR
}

\section{> INTRODUÇÃO}

Os sistemas de pagamento tornaram-se elementos cada vez mais críticos na política de saúde e o interesse por eles aumentou à medida que os países em todo o mundo tentaram controlar o aumento das despesas e dos custos, melhorar a qualidade e utilizar os recursos disponíveis de forma mais eficaz (Appleby et al, 2012). Há evidências de que um os altos custos da saúde estão relacionados com o modelo de pagamento de prestadores de saúde que os países adotam (Lorenzoni, Belloni, \& Sassi, 2014).

\section{$>$ OBJETIVO}

Nesse estudo, o objetivo é verificar qual o impacto de alguns dos fatores associados ao crescimento do gasto per capita com saúde. O estudo pretende verificar especificamente (i) a relevância do modelo de pagamento hospitalar para o crescimento do gasto com saúde per capita. Para tanto, foi utilizado um modelo de dados em painel constituído de 40 países acompanhados por 14 anos.

\section{RESULTADOS}

Resumidamente, os resultados indicaram que os países que não adotaram pagamento hospitalar prospectivo de forma mais prevalente possuem uma taxa média de crescimento do gasto com saúde per capita $(4,3 \%)$ superior à taxa média de crescimento dos países que adotam esse modelo $(2,2 \%)$ (Figura 1).
Figura 1. Distribuição dos países entre os que adotam e os que não adotam majoritariamente o modelo de pagamento prospectivo e a taxa média de crescimento do gasto com saúde per capita.

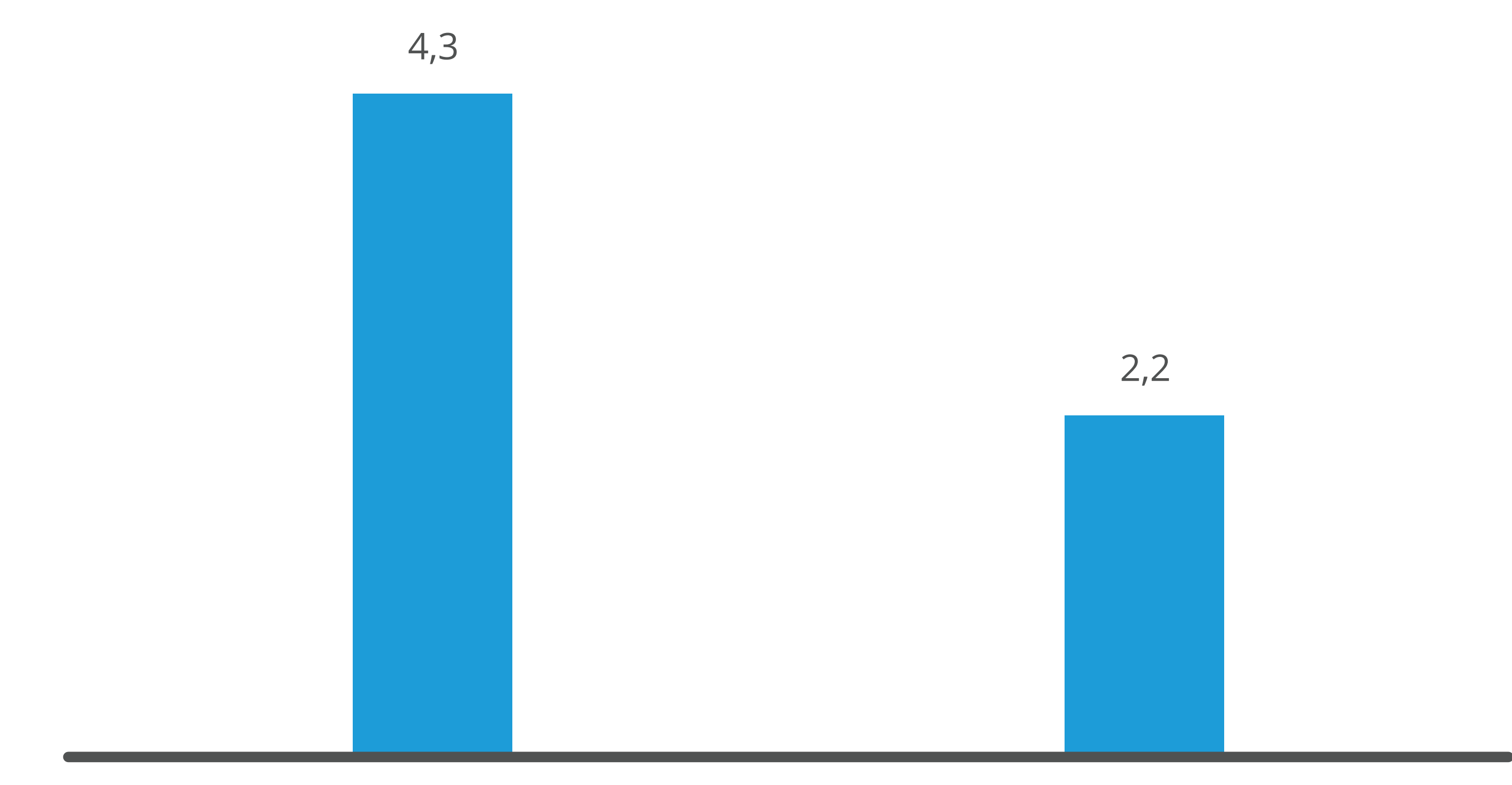

Modelo de pagamento Retrospectivo Modelo de pagamento Prospectivo

Fonte: Elaboração própria.

Nota-se que os países que usam o modelo prospectivo apresentam os maiores níveis de gasto per capita com saúde (apesar de apresentarem as menores taxas de crescimento, como mencionado anteriormente) também tem a maior média de aumento da proporção de idosos. Esses países têm envelhecido de forma mais rápida do que os países que ainda usam o fee-for-service e que, em geral, apresentam nível de gasto per capita mais baixo mas taxa de crescimento desse gasto mais elevada.

\section{CONCLUSÕES}

Diante desses resultados, evidencia-se a preocupante situação do Brasil, pois além de apresentar crescimento dos gastos com saúde mesmo nos anos em que o PIB sofreu retração, ainda adota majoritariamente o modelo de pagamento fee-for-service para pagamento hospitalar, tanto no setor privado quanto no público. 